Thorax (1973), 28, 313.

\title{
Fetal and childhood development of the intrapulmonary veins in man-branching pattern and structure
}

\author{
ALISON HISLOP and LYNNE REID \\ Department of Experimental Pathology, Cardiothoracic Institute, Brompton Hospital, London S.W.3
}

\begin{abstract}
The drainage pattern and the structure of the pulmonary veins have been described quantitatively in a series of fetal and child lungs after injection of the veins with a radio-opaque medium. The drainage pattern of the pre-acinar region is complete by half-way through gestation and corresponds with the growth of the pulmonary arteries. There is new growth of veins within the acinus during childhood. Four types of veins arising from five peripheral sites have been described. The change in dimensions with age have also been measured. A measurable muscle layer could not be found in the walls of the veins before birth though some muscle cells were present from 28 weeks of gestation. The thickness of the muscle coat in any vein was similar at birth and in a 3-and 10-year-old child and in all cases was less than in a pulmonary artery of the same size. The muscle cells were of smaller diameter in the veins than in the arteries. Along any venous pathway between a non-muscular and muscular structure was a region where part of the wall was muscular: these veins were termed partially muscular. Their distribution by size was similar at all ages.
\end{abstract}

The pulmonary venous system has not been studied as extensively as the arterial but its functional importance is becoming increasingly apparent. The veins have been shown to be active, in response to vasoconstrictive drugs (Rudolf, 1962 ; Hyman, 1969) and by serving as a reservoir to permit increased flow without a change in pressure (DePasquale, Hyman, and Burch, 1965).

The segmental arrangement of the veins has been described in detail by Boyden (1955) but not details of the intrapulmonary branching pattern. Miller (1937) reported the position of the pulmonary veins within the lung in dogs as being midway between the bronchus and its subdivisions, and that in their course to the hilum they are in connective tissue sheaths. Knisely (1960), using open chest illumination on live animals, described the postcapillary pattern of capillaries either entering other vessels at right angles or merging at acute angles.

Early embryonic development of the pulmonary veins from the splanchnic plexus and their connection with the left atrium has been described by Aüer (1948), Butler (1952), and Neill (1956) but later fetal development has not been recorded.

Harris and Heath (1962) described the uninjected veins of the adult as containing relatively little muscle, 'irregular in thickness'. Wagenvoort, Heath, and Edwards (1964) found muscle in venules as small as $80 \mu \mathrm{m}$. Brenner (1935) had noted that in larger vessels there was no demarcation between media and adventitia and that wall thickness increased with external diameter. Dammann and Ferencz (1956) noted that in the newborn the vein walls were thinner than in the adult while Wagenvoort (1970) believed that there was no fundamental difference in structure between them. Detailed studies of vein growth during intra-uterine life and childhood, using precise measuring techniques after injection as for the arteries (Hislop and Reid, 1972, 1973), are described below.

\section{MATERIAL AND METHODS}

The intrapulmonary venous system has been studied in six normal fetal lungs from five fetuses, obtained either at abortion or from stillborn infants, and in one lung from each of two normal children, aged 3 and 10 years, who died as a result of domestic accidents.

The veins of the lungs were injected with barium sulphate/gelatine suspension at $60^{\circ} \mathrm{C}$ and a pressure of $100 \mathrm{~cm}$ water, the usual departmental method for artery injection (Hislop, 1971; Hislop and Reid, 
1970). This high pressure was found necessary for full injection even of the low pressure venous system. The lungs were then inflated and fixed with formol saline. Radiographs of each specimen were made and on these the pattern of drainage of the veins was studied and, with the aid of a dissecting microscope, the size of the axial pathways.

Using serial sections the venous drainage pattern was studied in detail by microscopic reconstruction of the full length of an axial pathway from two cases of 20 and 28 weeks' gestation and of the peripheral centimetre in the case of the two children.

From random sections the structure was related to size of vein and the extension of muscle into small vessels was estimated by the same methods that have been applied to injected arteries (Davies and Reid, 1970 ; Hislop and Reid, 1970).

\section{RESULTS}

\section{THE DRAINAGE PATTERN}

Figure 1 shows a venogram and an arteriogram of the left lung of a fetus of 28 weeks' gestation. These can be distinguished from each other by the larger number of right-angled tributaries and the denser background haze in the venogram. Measurements on a series of venograms showed, with age, an increase in diameter and length of main pathways; the pattern remained similar.

Microscopic reconstruction showed that the veins run independently of the airways and arteries, at the periphery of the acinus or lobule, and within their own connective tissue sheath. Veins were also found in the pleura and connective tissue septa. As was seen from the venograms the main veins increase in size from the periphery of the lung to the hilum and along their entire length receive tributaries of various sizes.

TYPES OF VEIN Axial veins were the main pathways from periphery to hilum. Three types of tributary entering the axial vein were recognized microscopically, the smallest being the type I supernumerary vein followed by the type II supernumerary and conventional vein. The 'conventional' veins, like the axial, run in their own connective tissue sheath. Along an axial pathway they were equivalent in number to the airway generations and the arteries accompanying them. These arteries Elliott (1964) termed 'conventional' and the veins, being equivalent, have also been described by this term. These veins entered the axial vein at an acute angle, were nearly as large as the axial vein, and increased its size when they joined. They were already some distance from the capillary bed they drained and had themselves received many tributaries. In this study the con- $\stackrel{\overrightarrow{\vec{D}}}{\stackrel{\overrightarrow{0}}{+}}$ ventional veins were numbered from periphery to hilum as generations.

Two other types of tributary, smaller than con- $\frac{\bar{c}}{\frac{D}{D}}$ ventional veins, were called 'supernumerary', the $\stackrel{\mathbb{D}}{\Omega}$

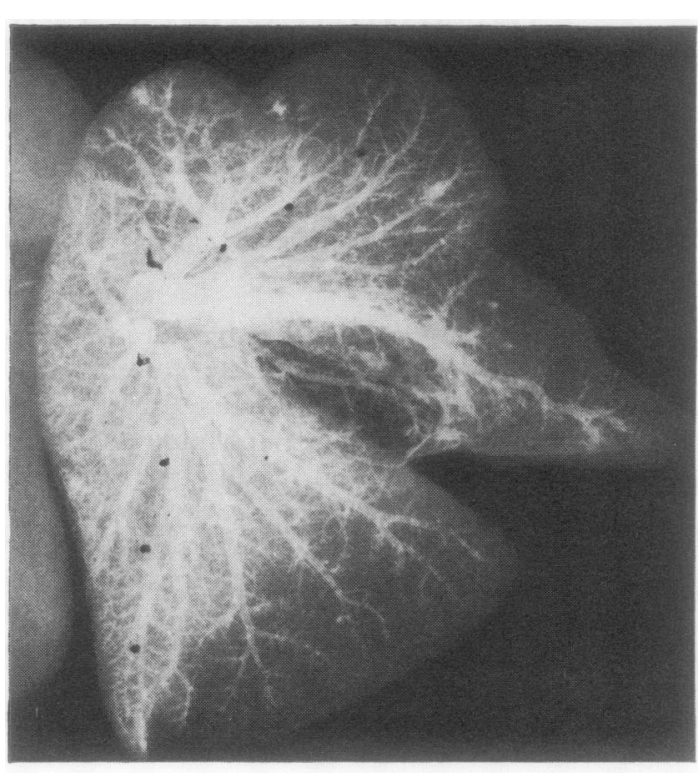

(a)

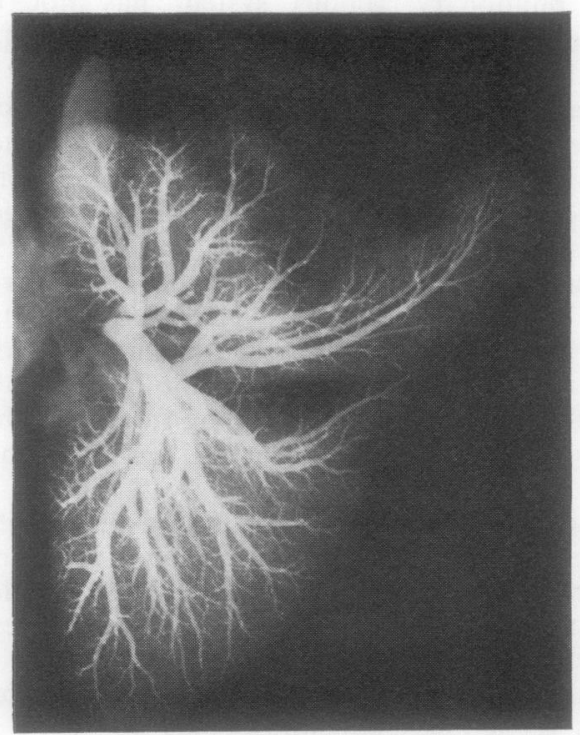

(b)

FIG. 1. (a) Venogram and (b) arteriogram of the left lungs of fetuses of 28 weeks' gestation. The vessels have been injected with a barium sulphate/gelatine solution. Tributary veins enter larger veins at right angles. $(\times 1 \cdot 5)$ 
term used by Elliott (1964) to describe the additional arterial branches. These vessels entered the main vein at right angles and did not increase the size of the receiving vessel. The type I supernumerary vein drained the lung tissue immediately surrounding the axial vein and only occasionally itself received tributaries. It had no collagen sheath and passed directly through the main vein sheath into the vein (Fig. 2). The type II supernumerary vein was, on average, larger in external diameter than the type I, had come further from the capillary bed, and had already received several postcapillary tributaries. At their junction with an axial vein they were large enough to have a thin collagenous sheath continuous with the axial vein sheath (Fig. 2). They increased rapidly in size from their origin to their junction with the axial veins.

All three types of tributary might be found anywhere along the length of an axial vein. The largest conventional and the type II veins were found near the hilum and decreased in diameter towards the periphery. All four types of vessel could be identified in the lungs of 3 and 10 years and at 28 weeks' gestation, but at 20 weeks' gestation the two types of supernumerary vein could not be distinguished as easily as later.

PERIPHERAL ORIGINS OF VEINS In the lungs of the 3-and 10-year-old it was possible to identify five sites of origin of the venous tributaries: (1) alveolar walls, (2) points of division of alveolar ducts, (3) walls of bronchioli, (4) the pleura, and (5) connective tissue septa and sheaths. In the lungs of fetuses of 20 and 28 weeks' gestation the acinar region was not complete (Loosli and

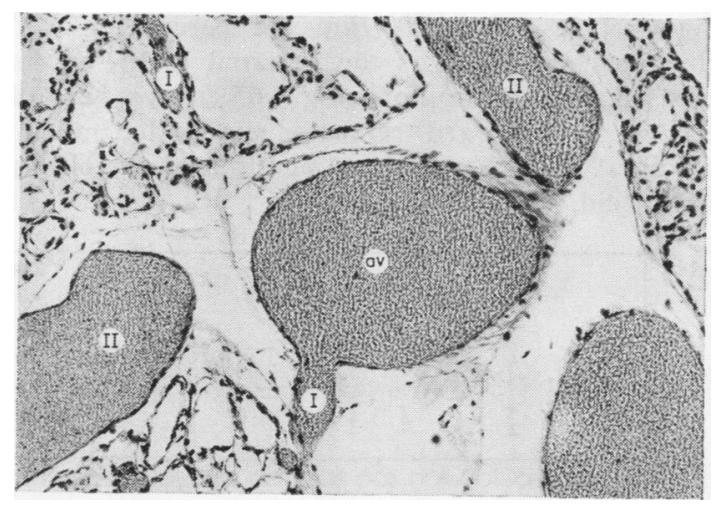

FIG. 2. Photomicrograph of type I (I) and type II (II) supernumerary veins entering an axial vein (av) in the lung of a 28-week-old fetus. The veins contain barium sulphate/ gelatine solution. (Haematoxylin and eosin $\times 108$ )
Potter, 1951), the small respiratory bronchioli opening into 'primitive saccules' (Boyden, 1965) lined by thin epithelium overlying capillaries. Veins arose from the saccular respiratory region and also the pleura, connective tissue septa, and the walls of airways.

CHANGING VENOUS PATTERN WITH AGE As was apparent from the venograms the length of the axial pathway increased with age. There was individual variation in the number of pre-acinar conventional veins joining an axial vein but, even at 20 weeks' gestation, all fell within the adult range of intrasegmental airway number determined by Hayward and Reid (1952). After birth new veins appeared within the acinus. At all ages there were more supernumerary than conventional veins (Fig. 3) and more of type I than of type II. The ratio of supernumerary to conventional veins was similar in all cases despite the difference in age and the part of the pathway traced, the range being $3 \cdot 5: 1$ to $4 \cdot 3: 1$. This is a higher ratio than is seen in the arterial system (Elliott and Reid, 1965; Hislop and Reid, 1972, 1973). Both conventional and supernumerary veins become more frequent towards the periphery. The ratio of supernumerary to conventional veins did not increase, however, nor was it higher in the acinus, as is seen in the arterial system.

All veins would seem to have grown at the same time as the arteries and airways, the preacinar drainage pattern thus being complete halfway through fetal life (Bucher and Reid, 1961; Hislop and Reid, 1972) and the intra-acinar pattern developing during childhood (Hislop and Reid, 1973).

In Fig. 3 the dimensions of the distal part of an axial pathway and its tributaries in a 3-yearold lung are shown. The trends were similar to those seen in all four cases studied by serial reconstruction.

An axial vein increased in diameter as it passed to the hilum. At a given distance from the periphery its diameter in all four cases was similar, showing that diameter was related to the distance from the capillary bed and not to the number of tributaries or to age. This feature was also noted in a study of the pulmonary arteries (Hislop and Reid, 1972).

The conventional venous tributaries generally increased in diameter towards the hilum and, with age, the size of all increased. They were smaller than the axial vein but larger than adjacent supernumerary veins. The type II veins were always larger on average than the type $I$. Over the distal region of the axial pathway the 


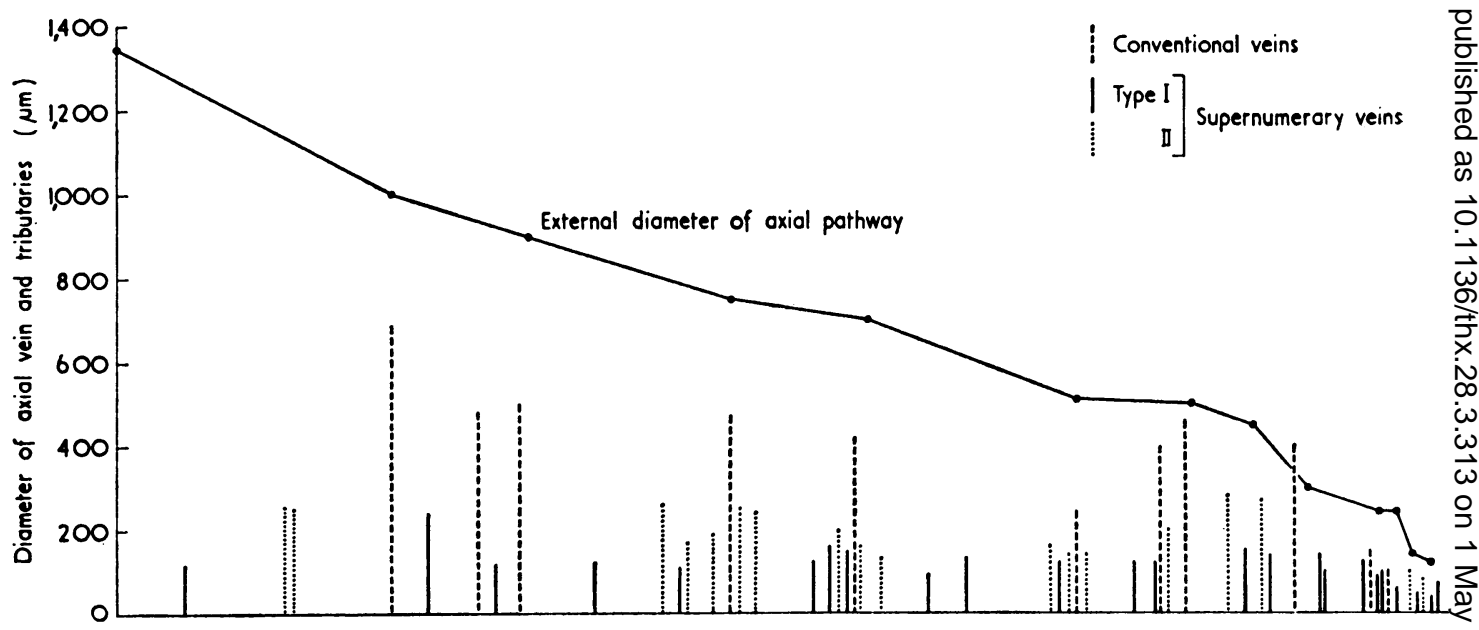

FIG. 3. Diagram representing the drainage pattern at the periphery of the lung of a 3-year-old normal child. The diameter $\overrightarrow{0}$ of axial, of conventional, and of both types of supernumerary vein tributaries is shown. Actual length of pathway is $11.07 \mathrm{~mm} . \mathrm{\omega}$

type II supernumerary veins increased in size with age while after birth the type I vessels did not, which may be accounted for by the fact that these are new vessels or that, by definition, they are the smallest and that this does not change with age.

\section{STRUCTURE OF THE VEIN WALL}

At 20 weeks' gestation no muscle was seen in the wall of even the largest veins within the lung, the wall consisting of a layer of endothelial cells resting on collagen fibres and with occasional small elastic fibres.

By 28 weeks' gestation, scattered muscle bundles could be seen but only in incompletely distended veins; these did not form a continuous layer around the vessel. At birth, even in a fully injected vein, it was possible to see a continuous layer of muscle between the endothelium and collagen. No elastic lamina, either internal or external, was present and the outer edge of the muscle was not well defined. This case was the youngest in which it was possible to measure the thickness of the muscle coat of the veins.

In the lungs of the 3- and 10-year-old children the wall structure of the veins was better developed. The postcapillary vessels had an endothelial lining. In slightly larger vessels an internal elastic lamina and an occasional muscle fibre had appeared; these were similar in structure to the partially muscular arteries (Elliott, 1964) and have been termed 'partially muscular veins'. Larger veins had a continuous muscle coat which was thicker in the larger vessel but even in the largest veins no definite external elastic lamina was seen, only an increasing amount of elastic and collagen between the muscle cells.

WALL THICKNESS Wall thickness could be mea-D sured on the veins in the 39-week fetus and in the 3- and 10-year-old children, and was taken to be the thickness from the internal elastic lamina to the most external muscle fibre within the collagen of the adventitia ; external diameter was taken as the distance between the mosto external muscle fibres. The percentage wall thick-0 ness was estimated by relating twice the wallo thickness to the external diameter. For all three 3 . cases the wall thickness was similar for veins overio $300 \mu \mathrm{m}$ external diameter, an average of $1.5 \%$ (Fig. 4) and a range of only 0.5 to $2.4 \%$. Ino veins of less than $300 \mu \mathrm{m}$ the percentage wall thickness increased as the external diameter de 0 creased, the maximum being $4.65 \%$ in a vein of $85 \mu \mathrm{m}$. This upward trend was similar to, but not as great as, that seen in small arteries (Hislops and Reid, 1972, 1973).

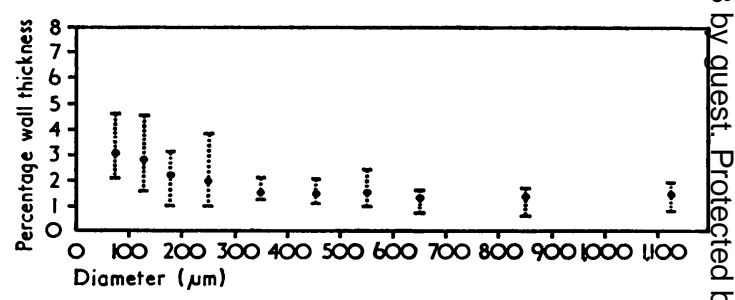

FIG. 4. Percentage wall thickness of veins related toे external diameter from lungs of cases aged 39 weekso gestation, 3 and 10 years. The mean and range for eact diameter size group are shown. 
EXTENT OF MUSCLE At 39 weeks' gestation the smallest vein in which muscle was seen, even though not forming a continuous coat, was 105 $\mu \mathrm{m}$, at 3 years $130 \mu \mathrm{m}$, and at 10 years $70 \mu \mathrm{m}$, the largest non-muscular veins being $120 \mu \mathrm{m}$, $200 \mu \mathrm{m}$, and $127 \mu \mathrm{m}$ respectively. There seemed little change with age. Overlap occurred between the size ranges for muscular, partially muscular, and non-muscular veins, in fact a mixed population in the small vessels similar to that seen in small arteries (Hislop and Reid, 1972, 1973).

\section{DISCUSSION}

It is possible to distinguish venograms from arteriograms despite the fact that the overall drainage pattern of the veins is similar to that seen on arteriograms with main veins corresponding to main branches of the pulmonary artery. The hilar arrangement, not described here, is different, and in the venograms the background haze is denser than in the arteriograms at any age and almost obscures the main vessels. This increase correlates with the higher density of veins observed per unit area of alveolar tissue than of arteries. The number of venous supernumerary tributaries along an axial pathway is greater than the number of arterial supernumeraries although their mean diameter is smaller than that of the arteries. The veins increased in size with age and lung volume but the vessels at a given distance from the periphery were of the same diameter, suggesting that the diameter of the vein is related to the volume of lung which it is draining in the same way that artery diameter relates to the volume of lung supplied (Hislop and Reid, 1972).

The veins have a drainage pattern corresponding to the artery supply, with a similar number of conventional vessels along a main pathway. There is also direct drainage of the alveolar region via supernumerary veins. These have a similar function to the supernumerary arteries in that they are available for collateral drainage if areas become blocked off or they may be used in recruitment when there is extra blood flow to be accommodated. It is these supernumeraries which may prevent a rise in pressure when flow increases (DePasquale et al., 1965).

The veins would seem to develop at the same time as the arteries and airways and are probably complete to the level of the acinus soon after 16 weeks' gestation-certainly by 20 weeks. They appear to grow in the same way as the arteries, conventional and supernumerary vessels appearing at the same time at the periphery as the proximal veins are increasing in size. In certain cases of congenital heart disease also, vein size follows the arterial. An increase in pulmonary blood flow was associated with an increase in both arterial and venous size and a decrease in flow with a reduction in both (Hislop, 1971).

For the first time three types of venous tributary have been identified and classified. The conventional veins are equivalent in number and size to conventional arteries and drain a considerable volume of lung. The two types of supernumerary vein both drain only tissue of the alveolar region. Elliott (1964) described two types of supernumerary arteries but it is unlikely that these correspond closely with the two venous types. The aberrant or 'short-course' arteries were less numerous and larger than the type II veins and eventually came to lie with airways and branched as conventional arteries. The other type of supernumerary artery - the accessory-supplied a larger area of lung than is drained by the type I vein ; it was relatively less in number but had a greater mean diameter than this vein. Both types of supernumerary vein would seem to correspond functionally to the accessory arteries in that they drain the 'potentially dry areas' (Elliott, 1964) of the edge of the acinus.

As there are more supernumerary veins than arteries there would seem to be a larger number of vessels leaving than entering the capillary bed. In the pre-acinar region this may be due to the additional drainage to the pulmonary vein from the bronchi that are supplied by bronchial arteries, but the intra-acinar region also shows a higher concentration per unit area of veins than arteries ; this may contribute to the lower pressure in the venous system.

Miller (1937) described in dogs four sites of origin for the veins-the pleura, capillary bed of alveoli, capillary network of the alveolar ducts, and the bronchial branching point. In the present study these four origins could be identified after birth and, in addition, veins were seen to arise from the walls of the terminal bronchioli and respiratory bronchioli at points other than their branching point. These were probably draining the zone supplied by bronchial arteries. In addition, small vessels drained the connective tissue septa and the sheaths of the vessels. These differences probably represent species variation. In the fetal cases the alveolar region was not fully differentiated and it was not possible to identify the separate sites of origin seen in the child.

As noted by Knisely (1960), the veins leaving 
the capillary bed entered the larger veins at right angles using a less circuitous route than the branching pulmonary arteries. The hydrodynamic significance of this is not known.

STRUCTURE OF THE VEIN WALL The precise injection and measuring technique described here has been applied for the first time to the venous system. The structure in the 10-year-old lung is similar to that described by Wagenvoort (1970) for the adult uninjected lung. He found muscle first appearing on vessels of $40-50 \mu \mathrm{m}$. In the present study the smallest muscular vessels were slightly larger, probably because of distension. Brenner (1935) did not describe muscle in venules below $150 \mu \mathrm{m}$ and it seems likely that he disregarded vessels without a complete muscle coat. The smallest wholly muscular vessel in this 10year-old was $200 \mu \mathrm{m}$ in diameter.

Partially muscular veins have been described here as a separate entity. Along any venous path they are found between non-muscular and muscular vessels where the muscle cells are just appearing and form a spiral but the fibres are not continuous laterally. The level of the change varies along different pathways and, as with the arteries, there is an overlap of size ranges for the three types. The partially muscular veins are therefore similar to the partially muscular arteries and are found in a similar size range. They are probably the same vessels described by Takino and Miyake (1936) in uninjected material as having a 'string of beads' appearance.

To measure the actual medial wall thickness was difficult because of the lack of an external elastic lamina, a feature noted by Wagenvoort (1970). Samuelson, Becker, and Wagenvoort (1970) found it possible to measure wall thickness in the youngest case they studied at 28 weeks' gestation. In the present series of injected lungs wall thickness was not measured at this age because in veins of all sizes muscle was discontinuous and at 20 weeks not even present. In a vein of given size, Samuelson et al. (1970) found a slight rise in wall thickness up to 34 weeks, after which time to adulthood there was no change in percentage wall thickness. In the present series this was confirmed in cases of 39 weeks' gestation and older. We did not find the increase in wall thickness between birth and adulthood for each size of vein as described by Dammann and Ferencz (1956).

At all ages the percentage wall thickness is lower in the veins than in the arteries. The thinnest muscular wall was only $1 \mu \mathrm{m}$ in the veins compared with $2.5 \mu \mathrm{m}$ in the arteries (Hislop, 1971).
This suggests that there may be some difference the muscle cells between veins and arteries. A호 with the arteries, vessels below $300 \mu \mathrm{m}$ show aff increase in relative wall thickness.

The reduction in wall thickness in the veins i\& doubtless related to the pressure within them which, in the adult, is about half that in the arteries. Muscle will increase in the veins with increase in pressure. Smiley, Jaques, and Campbelf (1966) showed that reversal of pulmonary bloot flow in dogs, producing arterial pressures in the veins, led to medial hypertrophy. Samuelson et a (1970) demonstrated venous medial thickening in cases with mitral stenosis and anomalous pul $\vec{\omega}$ monary venous drainage.

In a series of young children with congenitat heart disease, producing an increased pulmonar blood flow and increase in pressure, arterial an venous muscle hypertrophy was found. Venous medial hypertrophy was obvious if arterial musclet hypertrophy was gross, which suggested that the venous were secondary to the arterial changes (Hislop, 1971).

During fetal life the pulmonary arteries are more muscular than in the adult while the vein are less. It is possible that the high resistance in the pulmonary arteries during fetal life allows se्य little blood through to the veins that little muscle 3 is required, but the increased muscle in the veins in childhood is not just a reaction to increase in flow as there is a continuous rise in muscle throughout fetal life.

The growth in size and number of the veins and their branching pattern follow a simila pattern to that of the arteries although musclè development in the venous part of the pulmonarys circulation lags behind that in the arteries.

We should like to thank Dr. H. Kay of the Roya Marsden Hospital, Dr. J. D. Lavertine of HillingdonHospital, Professor K. Simpson of Guy's HospitalN and Dr. J. Wigglesworth of Hammersmith Hospita/ who have supplied us with normal fetal and child lungs for this study.

The study was supported by the Research Como mittee of the Board of Governors of the Bromptom Hospital and is part of the work accepted for the degree of Ph.D. London University. A.H. is in receipen of a grant from the British Heart Foundation.

\section{REFERENCES}

Aüer, J. (1948). The development of the human pulmonar vein and its major variations. Anat. Rec., 101, 581.

Boyden, E. A. (1955). Segmental Anatomy of the Lungs McGraw-Hill, New York.

(1965). The terminal air sacs and their blood supply a 37-day infant lung. Amer. J. Anat., 116, 413. 
Brenner, O. (1935). Pathology of the vessels of the pulmonary circulation. Part 1. Arch. intern. Med., 56, 211.

Bucher, U., and Reid, L. (1961). Development of the intrasegmental bronchial tree: the pattern of branching and development of cartilage at various stages of intrauterine life. Thorax, 16, 207.

Butler, H. (1952). Some derivatives of the foregut venous plexus of the albino rat, with reference to man. J. Anat., (Lond.), 86, 95.

Dammann, J. F., and Ferencz, C. (1956). The significance of the pulmonary vascular bed in congenital heart disease. I. Normal lungs. II. Malformations of the heart in which there is pulmonary stenosis. Amer. Heart J., 52, 7.

Davies, G., and Reid, L. (1970). Growth of the alveoli and pulmonary arteries in childhood. Thorax, 25, 669.

DePasquale, N. P., Hyman, A. L., and Burch, G. E. (1965). Response of the pulmonary vein to rapid blood transfusion in intact dogs. J. Lab. clin. Med., 65, 122.

Elliott, F. M. (1964). The pulmonary ariery system in normal and diseased lungs-structure in rciation to pattern of branching. Ph.D. thesis, University of London.

monary artery and its branching pattern. Clin. Radiol., 16, 193.

Harris, P., and Heath, D. (1962). The Human Pulmonary Circulation. Livingstone, Edinburgh.

Hayward, J., and Reid, L. M. (1952). Observations on the anatomy of the intrasegmental bronchial tree. Thorax, $7,89$.

Hislop, A. (1971). The fetal and childhood development of the pulmonary circulation and its disturbance in certain types of congenital heart disease. Ph.D. thesis, London University.

- and Reid, L. (1970). New pathological findings in emphysema of childhood: 1. Polyalveolar lobe with emphysema. Thorax, 25, 682 .
(1972). Intra-pulmonary arterial development during fetal life-branching pattern and structure. J. Anat., 113, 35.

(1973). Pulmonary arterial development during childhood-branching pattern and structure. Thorax, 28, 129.

Hyman, A. L. (1969). The direct effects of vasoactive agents on pulmonary veins. Studies of responses to acetylcholine, serotonin, histamine and isoproterenol in intact dogs. J. Pharmacol. exp. Ther., 168, 96.

Knisely, W. H. (1960). In vivo architecture of blood vessels supplying and draining alveoli. Amer. Rev. resp. Dis., 81, 735.

Loosli, C. G., and Potter, E. L. (1951). The prenatal development of the human lung (abstract). Anat. Rec., 109, 320.

Miller, W. S. (1937). The Lung. Thomas Springfield, Illinois.

Neill, C. A. (1956). Development of the pulmonary veins; with reference to the embryology of anomalies of pulmonary venous return. Pediatrics, 18, 880 .

Rudolph, A. M. (1962). Pulmonary venomotor activity. Med. thorac. (Basel), 19, 376.

Samuelson, A., Becker, A. E., and Wagenvoort, C. A. (1970). A morphometric study of pulmonary veins in normal infants and infants with congenital heart disease. Arch. Path., 90, 112.

Smiley, R. H., Jaques, W. E., and Campbell, G. S. (1966). Pulmonary vascular changes in lung lobes with reversed pulmonary blood flow. Surgery, 59, 529.

Takino, M., and Miyake, S. (1936). Uber die Besonderheiten der Arteria und Vena pulmonalis bei verschiedenen Tieren, besonders beim Menschen. Acta Sch. med. Univ., Kioto, 18, 226.

Wagenvoort, C. A. (1970). Morphologic changes in intrapulmonary veins. Human Path., 1, 205.

—, Heath, D., and Edwards, J. E. (1964). The Pathology of the Pulmonary Vasculature. Thomas, Springfield, Illinois. 